\title{
CREATING FUTURES: RESIDENTIAL CARE HOMES IN HUNGARY AND SWITZERLAND COLLABORATIVELY DEVELOP THEIR CAPACITY TO EMPOWER CHILDREN AND YOUTH TO ACTIVELY REALISE THEIR OWN FUTURES
}

\author{
Anna Schmid and Krisztián Herczeg
}

\begin{abstract}
Child and youth homes in Hungary and Switzerland want to increase the chances that the approximately 1,000 children and youth in their care will transition well from residential care to other settings, will be fully included in society, and will live lives that they have reason to value. Key to this objective is the empowerment of the children and youth to take their development into their own hands, to develop ideas of a possible future, and to pursue these ideas actively and sustainably. In the project "Creating Futures", these homes plan to collect knowledge from children, youth, staff, and managers, as well as from the literature; to develop a framework of analysis to identify current good practices, and potentials for further development; and to implement a concrete pilot project in each home. Evaluations of the learning and development process and dissemination of publications complete the project. Throughout, there will be a strong focus on the voice of children and youth. Collaborating as a community of practice and within the context of expert network FICE International, the homes will make use of their diversity for stimulating learning and development on the individual, professional, and organisational levels. This paper describes the emergence and design of the planned project.
\end{abstract}

Keywords: child, youth, care leavers, residential care, quality development, empowerment, participation, protagonism, community of practice, Hungary, Switzerland, international

Acknowledgement: The authors thank Szilvia Szalontai for her valuable translation support during the writing of this paper.

Anna Schmid $\mathrm{PhD}$ (the corresponding author) is a lecturer and researcher at the Institute of Management and Social Policy at the School of Social Work of ZHAW Zurich University of Applied Sciences, Pfingstweidstrasse 96, P.O. Box 707, 8005 Zurich, Switzerland, and board member of FICE Switzerland. Email: anna.schmid@zhaw.ch

Krisztián Herczeg DJur is director of Cseppkö Child and Youth Home Centre, Cseppkő u. 74, 1025 Budapest, Hungary. He is a lecturer in Child Protection at the University of Pécs, and vice president of NENESZ, a member network of FICE International. Email: cseppgyermek@ cseppgyermek.hu 
International Journal of Child, Youth and Family Studies (2018) 9(1): 132-153

This paper presents the emergence of a Community of Practice $(\mathrm{CoP})$ of child and youth homes in Hungary and Switzerland and its development and design of a research and development project.

\section{Motivation}

The root of the Creating Futures project lies with a group that included four experts in child and youth care from child and youth homes, relevant authorities, and an expert network in Hungary; and a Swiss academic (the corresponding author) who specialises in organisation studies with a practice background in residential care. The group first came together in May 2015 at an event of FICE International ${ }^{1}$ in Serbia. In informal conversations during those proceedings they discovered a firm shared belief in children and youth's ${ }^{2}$ competencies, capacities, and potentials, as well as a commitment to promoting their inclusion, participation, and empowerment. They also discovered a mutual interest in personal and professional learning and in further developing the quality of residential child and youth care, and noticed that their conversations were made particularly rich and enjoyable by drawing on their diverse personalities, knowledge, experiences, and professional backgrounds, as well as on the different contexts of the two countries and their child and youth care systems and services.

Inspired by this experience, the idea emerged to join forces, learn from each other and with each other, and support each other in a concrete initiative with the aim of making a relevant contribution to aspects of quality development in residential care, thus benefiting children and youth in residential care concretely and effectively.

This idea was further strengthened during a first visit to Budapest by the corresponding author, which included conversations with the original group as well as opportunities to observe some of the daily work in one of the child and youth homes. This provided insight into residential and foster family services and collaboration with Roma organisations. Three months later, a visit to Zurich offered the Hungarian group an opportunity to meet two child and youth home directors from Switzerland who were also interested in collaborating, and to visit one of the homes and gain insight into its diverse services. They also met with the representative of the relevant authorities of the Canton of Zurich. Furthermore, Hungarian and Swiss representatives had a first opportunity to discuss questions of quality in residential care with each other, students, and other experts on the occasion of an international seminar offered by ZHAW Zurich University of Applied Sciences in collaboration with FICE Switzerland.

After this first phase in 2015, discussions continued in 2016 both within and between the countries with two goals: to build up a strong basis for collaboration, and to develop a topic of relevance to practice that would be at the heart of concrete collaborative work.

\footnotetext{
${ }^{1}$ FICE International is a worldwide network of professionals in the field of alternative child and youth care, founded in 1947 and present in more than 35 countries. See http://www.ficeinter.net.

${ }^{2}$ The term youth includes adolescents up to 18 years of age and young adults up to 26 years of age.
} 
International Journal of Child, Youth and Family Studies (2018) 9(1): 132-153

The group's starting point was the goal of a concrete and sustainable development initiative, with the belief that this could be best achieved if it drew on the capacities and potentials of the individual and contextual diversity of the persons and organisations involved. Members felt that an important first step was for the members in each country (not all of whom knew each other well) to form a strong group willing and able to work together, in order to then build a joint group with the partners from the other country. This was all the more necessary because membership in the group was entirely voluntary and not subject to any obligation, such as to an employer. Consequently, a structure for, and mechanisms of, voluntary collaboration based on relationships of trust, mutual interests, and both personal and joint commitment had to be created.

A fundamental concern of the two country groups in the initial stages of the collaboration was whether they would have "enough to offer" to the other country, and whether it would be possible to find topics of common interest that both groups would be able to work on. For example, it was felt that the education of staff members was at that time a more topical issue in Hungary than in Switzerland. Also, as economic pressures are greater in Hungary than in Switzerland, Swiss members of the CoP hypothesised that perhaps Hungarian youth in residential care would be more "grateful" and "motivated" than Swiss youth in a system "where people are looked after and maintained even if they display no motivation or effort whatsoever"3, as a Swiss child and youth home director put it (personal communication, November 10, 2016).

In August of 2016, the corresponding author, now coordinator of the group, had the opportunity to visit further child and youth homes in Budapest. In October of that year, the Hungarian group again visited Zurich for meetings with their Swiss counterparts and had the opportunity to visit another of the homes involved. Subsequently, the Swiss had the opportunity to visit the Hungarian homes during joint CoP meetings in Budapest in June of 2017. Here, the $\mathrm{CoP}$ received input from exploratory focus group discussions with seven youths from the Swiss and 50 youths from the Hungarian homes, with 10 of the latter actively participating in the meetings.

In the course of discussions, it became apparent that the two countries complemented and contrasted with each other in a way conducive to a joint initiative. Both shared an expert community currently focusing strongly on quality in residential care and its development according to international guidelines and the current state of the art in the field. The countries differed from each other in social, political, and cultural contexts as well as some aspects of practice; a fact that the group members from both countries regarded as enriching for their joint reflection, discussion, and development.

In the course of 2016, the group decided to regard itself as a CoP, as defined by WengerTrayner and Wenger-Trayner (2015): "Communities of practice are groups of people who share

\footnotetext{
${ }^{3}$ Translated from German by the corresponding author.
} 
a concern or a passion for something they do, and learn how to do it better as they interact regularly." (p. 1). In all cases, the key elements of a CoP, according to Wenger-Trayner and Wenger-Trayner (2015), are:

- the domain, where members are brought together by a learning need they share (whether this shared learning need is explicit or not and whether learning is the motivation for their coming together or a by-product of it);

- the community, wherein their collective learning becomes a bond among them over time (experienced in various ways and thus not a source of homogeneity); and

- the practice, in which their interactions produce resources that affect their practice (whether they engage in actual practice together or separately).

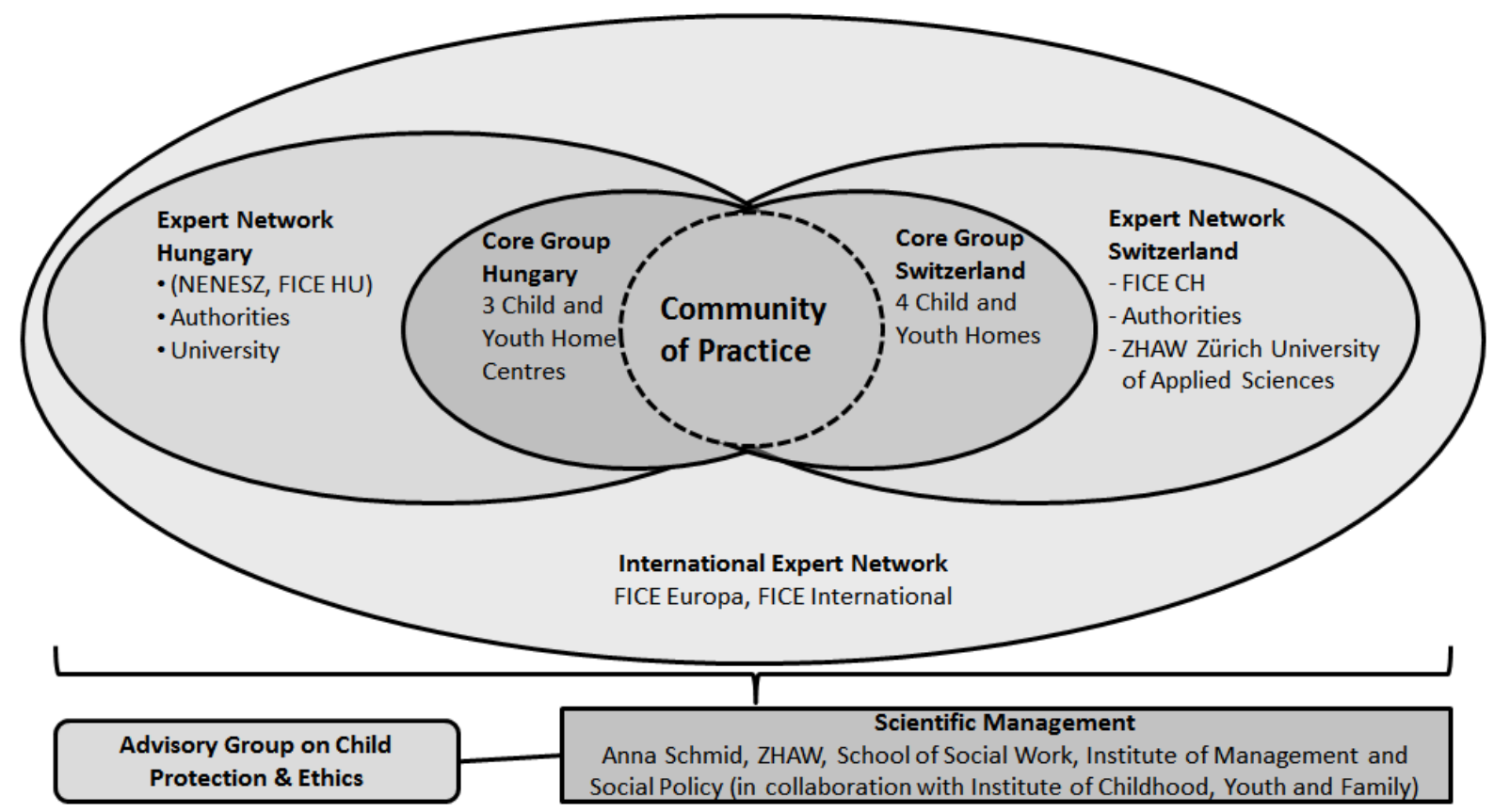

Figure 1 The CoP and its expert network.

By June of 2017, this CoP included three Hungarian child and youth home centres in Budapest and their representatives as well as two Swiss child and youth homes and their representatives in the Zurich area; two more homes from the Zurich area were in the process of joining. Together, these homes represented approximately 1,000 children and youths in their care. The CoP also maintains an exchange and collaboration with the relevant authorities in both countries. Furthermore, it has links to international exchange and expertise, in particular with the FICE International network of experts in alternative care of children and youth, which is present in 35 different countries. Additionally, an independent group of experts from both countries advises the CoP regarding issues of child protection and ethics. The overall and scientific 
International Journal of Child, Youth and Family Studies (2018) 9(1): 132-153

coordination of the $\mathrm{CoP}$ and its project Creating Futures lies with the corresponding author of this paper.

\section{Problem Identification}

From the beginning, the Hungarian and Swiss CoP members were not only concerned with building up a collaboration, but also engaged in finding a joint focus topic to collaborate on, discussing candidate topics that they felt were of relevance to their current practice.

In these discussions, the Hungarian group mentioned a firm belief that "every child has talents", and described the successful talent development programme Varázscsepp [Magic Drop], which had been started by one of the homes represented in the group and then had been extended to a large number of residential care homes throughout the country. Anecdotally, they mentioned success stories such as that of "the teenagers who said that they were not interested in anything", but who, with encouragement, found something in the areas of culture, sport, or the professions that they liked and were able to do well. By doing so, they were able to engage in positive activities rather than harmful ones, take advantage of the opportunities for exchange with others that these offered, strengthen their self-esteem, and develop skills, resulting in positive, enjoyable experiences. As well as contributing to their inclusion, this helped them to overcome crises and difficulties, change their motivation and outlook on life, and generally strengthen their resilience. Interestingly, the director of that home described a similar moment in his own life that had not only had a great impact on his personal and professional development, but that had also inspired this approach. On this basis, the Hungarian group had a strong interest in further empowering children and youth to discover and develop their talents, and cited organisational conditions and, in particular, staff's attitudes and quality of work as most relevant to that objective.

At the same time, the transition of adolescents into more, or totally, independent adulthood was a topic mentioned time and again. For example, the Hungarian members voiced concerns regarding young adult care leavers who struggle to "find their own feet" in a sustainable manner.

On an organisational level, the Hungarian group mentioned a difficulty in finding wellsuited staff, and, in this context, also mentioned issues concerning the education, management, and development of staff, citing the varying levels of the staff's formal education and practical experience. For a joint initiative by the CoP, they requested that two conditions be adhered to: (a) the focus should be on real life challenges and experiences in everyday practice in residential care; and (b) children and youth had to be included in the collaboration, as experts regarding their own lives and the institutions in which they live. This latter condition was partly based on the homes' positive experiences with protagonism and participation in the democratically elected child and youth councils present in many homes in Hungary, but was also based on experiences such as the public "Child and Youth Parliament" that one of the group members was actively involved in. A further expectation was that children and youth from the two countries should 
have opportunities to meet and thus gain insight into the other country, its culture, and ways of life.

The Swiss group echoed the topics of their Hungarian colleagues, mentioning a variety of current activities aimed at strengthening children and youth's motivation and resilience and supporting them in building their lives, while also referring to concerns regarding adolescents and young adult care leavers being able to "find their own feet" and leading "good" lives (in the sense of lives they had reason to value) in a sustainable manner. One of the Swiss youth home directors said that he had noticed that the adolescents coming to his home seemed increasingly "more challenging" in the sense of coming from complex situations with a whole range of problems. He felt that these adolescents often were "not very motivated and difficult to motivate to take their development into their own hands" and to collaborate actively in the services and activities provided by the youth home. In his view, an important question would be:

What does an adolescent need to open a door? Sometimes, we try many things but seemingly without effect. Then, suddenly, there is a change in the adolescent and they start taking their development into their own hands, and we wonder what made this possible all of a sudden. What are the moments in which change and development become possible for the adolescent? ${ }^{4}$ (personal communication, June $8,2016)$

One Swiss youth home director (personal communication, April 6, 2016) mentioned that what he noticed most about the Hungarian colleagues when first meeting them was their engagement. He felt that the Hungarian children's home directors in the group showed an engagement and commitment towards each individual child that went beyond "doing the job", and that they did their work with much passion (the German expression is Herzblut [heart blood]). He felt that, with staff turnover being high in Switzerland, employees' attitudes have changed, in the sense that many see their work in a child and youth home as one of several steps in their professional development, as a job rather than a personal, lifelong engagement. He mentioned the following two questions as being linked to this issue: "What is needed for children and youth to feel taken seriously and addressed as individuals in the collective context of a residential care home? What is needed for the home to establish and maintain a strong focus on the child or youth in his or her individuality?"5 Another child and youth home director from Switzerland (personal communication, June 17, 2016) echoed this, saying that he saw a certain risk that some recent developments (e.g., the adoption of Sozialraumorientierung [social spatial orientation $]^{6}$ by some Swiss child and youth services) and the planned (as of 2016) expansion of

\footnotetext{
${ }^{4}$ Translated from German by the corresponding author.

5 Translated from German by the corresponding author.

${ }^{6}$ Social spatial orientation is an approach adopted in some areas of social work and social pedagogy in Germanspeaking Europe. Rather than focusing on pedagogical work with individuals, it focuses on creating living contexts and conditions that allow persons to deal better with difficult life situations.
} 
International Journal of Child, Youth and Family Studies (2018) 9(1): 132-153

ambulatory services might carry a certain risk that the individual child will not be sufficiently taken into account, or may pass "under the radar" altogether. He felt that in everything, the question "What about the child?" should be considered also, and added that it was particularly important to him to promote the development and realisation of individual life plans, and that this required of him and his child and youth home an open, even creative, attitude rather than a narrow, inappropriately normative one.

From these discussions, the Hungarian and Swiss partners agreed that they wanted to focus jointly and as a CoP on the following topic:

How can child and youth homes support and empower children and youth even more effectively in taking their development into their own hands, developing their own ideas of a possible future, and pursuing and realising these actively and sustainably?

In order to collaboratively increase its knowledge and to develop quality in the participating homes on the basis of concrete pilot projects, the CoP decided to design and implement a research and development project, Creating Futures, which will be described in the Present Investigation section below.

\section{Short Literature Survey}

A comprehensive literature survey regarding the focus topic and relevant subtopics will be part of the Creating Futures project's Phase 1, "Raising Knowledge" (see the Present Investigation section). The following short literature survey refers to selected aspects of the two main areas of the focus topic: (a) children and youth and their situation as they and their lives develop over a shorter or longer stay in residential care, and (b) child and youth homes as organisations providing services aimed at promoting and supporting this development. Those two areas could be visualised as meeting "in the middle", where coproduction happens between the organisation and the children and youth it serves, enabling them to take their development into their own hands and create and realise their own ideas of the future. In particular, this survey refers to a series of aspects that the CoP considered of particular relevance when designing the project.

Children and youth in or from residential care: A considerable number of care leavers from child and youth homes fail to establish a sustainable future for themselves. International research has shown that they do less well than their peers, exhibiting lower academic achievement, and higher rates of unemployment and detrimental experiences such as self-harm, homelessness, and participation in illegal activities. For example, in Switzerland, Gabriel and Stohler (2008, p. 203) cited a high risk of social exclusion for young people leaving care and an elevated mortality rate among young male care leavers, while Burgund and Rácz (2015, p. 103) mentioned that in Hungary, an estimated $40 \%$ of young people who passed through both care and 
International Journal of Child, Youth and Family Studies (2018) 9(1): 132-153

after-care (i.e., usually up to age 24) "become criminal, unemployed, homeless, prostitute or their children will grow up in [the] child protection system as well”.

Research has also shown that, internationally, children and youth who have been in residential care encounter particular economic and social disadvantages and barriers in their lives. Piller and Schnurr (2013, p. 12) identified structural disadvantages that are due to both the events that lead to young people being taken into care, and the biographical fact of having had a "stay in residential care". These disadvantages are compounded by the fact that children and adolescents in residential care have to enter the process of becoming independent significantly earlier than their peers who live in their families of origin, as Sievers, Thomas, and Zeller (2014, p. 13) have pointed out.

There are laws and provisions in place to sustain care leavers in the social support system and in employment. However, these vary both within and across national boundaries (Gabriel \& Stohler, 2008; Stohler \& Gehrig, 2015). In Hungary, for example, after-care provisions are in place up to age 24 for a large percentage of care leavers (Burgund \& Rácz, 2015), but this is the case in only some of the Swiss cantons. Overall, and in most countries, the implementation of support approaches that can specifically accommodate care leavers is far from comprehensive.

In addition, it has become increasingly clear that the issue runs deeper than questions of ensuring housing and employment or preventing crime, which are often the focus of support for care leavers (Stohler \& Gehrig, 2015). Children and youth's self-esteem, self-confidence, and self-efficacy are among the important factors to be strengthened.

Children and adolescents in residential care face greater challenges than their peers in developing an adequate notion of self, a sense of achievement, and plans for a possible future, as well as in actively pursuing and successfully realising their plans through their own efforts. For example, Macsenaere and Esser (2012, p. 87) found in their research on impact factors that many children and adolescents in child and youth homes have lived through poverty and have thereby experienced exclusion, contempt, a lack of appreciation and recognition, and a lack of selfefficacy (one's belief in one's ability to accomplish goals). Resource-oriented approaches support children and adolescents in discovering that they already have individual abilities on which they can build and that can contribute to their self-efficacy and self-confidence, and that distinguish them from their peers. Macsenaere and Esser (2012) emphasised additionally that children and adolescents can only experience self-efficacy in the context of a challenge that gives them the opportunity to experience themselves and their abilities and develop them further. Interviews with care leavers by Esser (2010; as cited in Macsenaere \& Esser, 2012, pp. 86-87) showed that leisure, musical, sports, creative, celebratory, and group activities were favourite activities that strengthened young people's protective personality factors. In addition, such activities were particularly important for children and adolescents who had no personal relationships in the home yet, as they gave them opportunities to meet people and form such relationships. 
International Journal of Child, Youth and Family Studies (2018) 9(1): 132-153

The statements of care leavers make it clear that they wish to be involved in such processes. For example, in 2016, a group of 60 care leavers from 15 countries formulated 10 standards for "leaving care" that were officially adopted by the more than 600 participating experts of the 33rd FICE Congress and 2nd CYC World Conference. Among the adopted standards were: "Every care leaver should be involved in their own care leaving plan and have a say in what has to be done", and "To be able to find and succeed in a job, every care leaver should get help to become aware of and get recognised with their potentials, so that they gather the chance to improve them" (FICE Standards Developed by Young Care Leavers, 2016, p. 1).

The child and youth home as an organisation: Child and youth homes do not develop the children and adolescents in their care. Rather, these organisations provide conditions, programmes, ways of working, persons of reference, relationships, experiences, and so on that are considered conducive to the children and youth's own development as they proceed on their life paths and build their futures. Child and youth homes are not simply providers of services, but spaces of living, living together, growing up, and socialisation. They are collective contexts in which children and adolescents live for some or most of their formative years, and that must, for example, "be able to recognise their individual potential, to value their dreams and abilities and turn them into talents", as Barros (2006, p. 99) stipulated.

As systems that contribute to change in people, child and youth homes are predominantly based on interactional relationships. Thus, the quality of face-to-face relationships and of interactions is a strong determinant of the success of any intervention, including sociopedagogical ones (Fretschner, 2011, p. 77). The child and youth home as organisation frames the interaction between staff and young people, both opening spaces and defining limits (Bommes \& Scherr, 2012, p. 256).

According to Wohlgemuth (1991), an organisation is a goal-oriented, relatively enduring, open sociotechnical system with formal and informal structures, a process of coming into being, and a relatively continuous process of change. Within, various social and technical elements interact in order to attain a performance conducive to fulfilling the organisation's purpose.

This means that, in order to create the organisational frame and spaces necessary for rendering services capable of reaching desired outcomes (such as children and youth developing ideas of the future) and contributing effectively to desired impacts, a child and youth home has to design and shape a number of elements both technical and social. Piber (2014, p. 73), for example, listed a "cultural subsystem" (including sense, purpose, mission statement, basic values, programmes, plans, etc.), a "social subsystem" (including organisational structure, hierarchy, relationships, knowledge, skills, management style, power, climate, etc.), and a

\footnotetext{
${ }^{7}$ Translated from Portuguese by the corresponding author.
} 
International Journal of Child, Youth and Family Studies (2018) 9(1): 132-153

"technical-instrumental subsystem" (including core and support processes, money, buildings, machines, instruments, vehicles, etc..$^{8}$

To a large extent, human interaction cannot be standardised, nor can its exact outcome be predicted (Drepper \& Tacke, 2010, p. 266). This means that joint reflection and learning by staff and children and youth is a promising approach to quality development, particularly when approaching a complex and highly individualised topic such as children and youth taking their development into their own hands and developing and realising their own ideas of the future.

Child and youth homes deliver person-oriented services. These are characterised by the fact that they are produced in coproduction between the home and those they serve: the performance of professional staff cannot be separated from the performance of the young people. The services offered by the home can only be successful if children and youth engage in them and succeed in drawing the maximum benefit for their own development from them. In order to illustrate and exemplify this, we will now consider the aspect of motivation.

What do children and adolescents need in order to draw the greatest possible benefit from what the home offers them for their own development? Participants of the CoP have mentioned "motivation" as an important factor for children and youth to take charge of their own development. According to Stangl (Stangl, n.d.), “A person's motivation to pursue a certain goal is influenced by situational stimuli, personal preferences, and the interaction between the two." 9 This means that motivation is not simply something that a person either has or does not have. Motivation depends not only on personal choice, but also on the situation, as well as on the internal and external consequences of the action. The motivation of an individual child or youth will be affected by the child or youth home, its employees, and the other children and youth, be it intentionally and directly (e.g., when completing explicit assessments) or unintentionally and indirectly during everyday communication.

To summarise, "motivation" denotes a complex phenomenon, one that is not directly observable. It is only possible to deduce motivation from action. Practical experience shows that misinterpretations can occur, particularly when employees are less educated or have less experience. For example, passive, rejecting, critical, or aggressive behaviours of adolescents do not necessarily indicate a lack of motivation but may have altogether different causes. We suggest that the work and offerings of the child and youth home may fall on the most fertile soil possible if motivation is present. At the same time, from the point of view of both social pedagogy and organisation studies, "to be motivated" is not only a task for the child or adolescent alone, but something that the child and youth home has to create and provide favourable conditions for. The actions stemming from that motivation will be a result of coproduction between the home and the young person. For this coproduction to be possible, the

\footnotetext{
${ }^{8}$ Translated from German by the corresponding author.

${ }^{9}$ Translated from German by the corresponding author.
} 
International Journal of Child, Youth and Family Studies (2018) 9(1): 132-153

home must not only provide appropriate structures, processes, resources, and so on, but also create spaces where coproduction and thus the development of children and youth as individuals, and as members of a group, of their families, and of society, can germinate, take root, and flourish.

Understanding children and youth as protagonists of their own development and making their participation in the child and youth home possible is most relevant from two points of view:

- From a sociopedagogical and psychological point of view, participation allows children and youth to build their self-esteem and develop the skills needed as they become more independent.

- From an organisational point of view, participation of children and youth is of vital importance to the performance and success (results, impact) of the child and youth home.

Thus, there is a clear interconnectedness of sociopedagogical and organisational issues in child and youth homes. The CoP strives to do justice to this interconnectedness in its collaboration and project.

\section{Present Investigation}

\section{Background}

Creating Futures, which the CoP has designed and is currently beginning to implement, is planned as a three-year research and development project. The formal start date depends on grant money being approved and is planned for the second half of 2017.

The CoP members are jointly responsible for developing and implementing the planned project. From each child and youth home at least one person with a responsible role and one young adult will take part in the CoP, whose members will be in constant dialogue, both virtual and, whenever possible, in person (see Figure 1). Each national community works in its national context as well as in collaboration with the partner country. In addition, each national CoP maintains a professional dialogue with a wider expert network. This includes the relevant member NGOs of FICE International, as these will play an important role in providing expert feedback on methods and results from multiple perspectives, and be instrumental in disseminating the results to all member institutions and countries and the wider expert field. Furthermore, it includes the relevant authorities in their functional responsibilities: The Hungarian Directorate General for Social Affairs and Child Protection and the Authority for Youth and Occupational Guidance of the Canton of Zurich support the project, contributing perspectives from their roles in coordinating the alternative care services supply system and their expertise in child protection and country-specific regulations, as well as supporting the dissemination of acquired knowledge. These authorities are in a position to encourage the implementation of recommendations or newly developed approaches in additional child and youth homes in their respective territories. Moreover, the wider expert network includes 
International Journal of Child, Youth and Family Studies (2018) 9(1): 132-153

universities, with a view to collaboration and exchange regarding scientific methods, dissemination, and the option of eventually developing materials for professional education and training.

The project's objective is to develop knowledge and approaches (e.g., methods, attitudes, processes, etc., and the organisational conditions that make them possible) that enable the participating child and youth homes to support and empower young people even more effectively in taking their development into their own hands, developing their own ideas of a possible future, and pursuing and realising these actively and sustainably.

Based on empirical research, the results will take the form of knowledge, ideas, and recommendations developed collaboratively by children, youth, staff, managers, and other experts, and tested in pilot projects, culminating in a model that may serve not only the member homes of the CoP, but others as well. With a view to ensuring sustainability, a further goal is to contribute to, and strengthen, learning and development capacity on the individual, professional, and organisational levels through the methodology used, as discussed below.

The project will contribute to closing a major research and knowledge gap. Much research exists regarding outcomes and impacts of residential care. For example, in Germany, there are the various publications of the project "Effect-oriented qualification of assistance for education" 10 and Macsenaere and Essers's (2012) publications; in Switzerland, there is the current project "Individual Outplacements: Administrative Decisions and Life Trajectories in the Canton of Zurich (1950-1990)"11, aimed at revealing the connections between care home upbringing, earlier life circumstances, and the later life course. However, little is known about the interplay between residential care settings and the development of individual ideas of the future by children and youth. By uncovering the implicit and explicit knowledge that children and youth, staff, managers, and other experts hold, a much wider discourse and more varied approaches to the issue become possible.

Even more importantly, the project will also contribute to reducing a gap in practice. Recent definitions of quality of residential care in legislation and in professional standards are important advances. While defining goals to be reached, however, they leave residential care homes to grapple with the challenge of reaching these goals with the limited resources available to them. Concrete implementation, therefore, is necessary and of great relevance. The project will achieve this by not only producing knowledge, but putting it to use, testing and refining it in a concrete pilot project in each participating child and youth home in a manner aimed at supporting the home's capacity for learning and development.

\footnotetext{
${ }^{10}$ http://www.wirkungsorientierte-jugendhilfe.de/

${ }^{11}$ https://www.zhaw.ch/en/socialwork/research/kindheit-jugend-und-familie/kinder-und-jugendhilfe/care-homeplacements-in-the-canton-of-zurich/
} 
International Journal of Child, Youth and Family Studies (2018) 9(1): 132-153

Last but not least, the project's high degree of diversity and participation as well as its methodology are aimed at stimulating and promoting sustained learning processes of all those involved on the personal, professional, and organisational levels. The insights gained on these three levels are expected to be rewarding for all participants.

\section{Methodology and Methods}

The CoP members have developed the methodology to be adopted in this project in collaboration. They regard children and youth as "experts of their everyday lives", as "coproducers" of the homes' services, and as protagonists of their own development (the main characters in their own stories). They also regard all members - managers, staff, children, and youth - of the child and youth homes as the main elements that constitute, maintain, and further develop the organisation. Consequently, the CoP members have agreed to ensure that the children, youth, staff, and managers of the participating homes are not only affected by the project but involved in it as experts in a participatory and collaborative manner. In this, their roles must go beyond providing information and include reflexive and interpretative processes as well as the elaboration of recommendations. Although this is a path as yet rarely taken by research and development projects, the $\mathrm{CoP}$ members are convinced that it indispensable if Creating Futures is to be a coherent, useful, sustainable, and credible project. Not least, they have chosen a focus on implicit and explicit practice-based knowledge in the homes with the intention of promoting the homes' development "from the inside out", contributing to sustainability by involving directly in designing the development those who will live this transformation, be it as managers or staff or as coproducing clientele.

The project consists of four modules and is planned for a duration of three years.

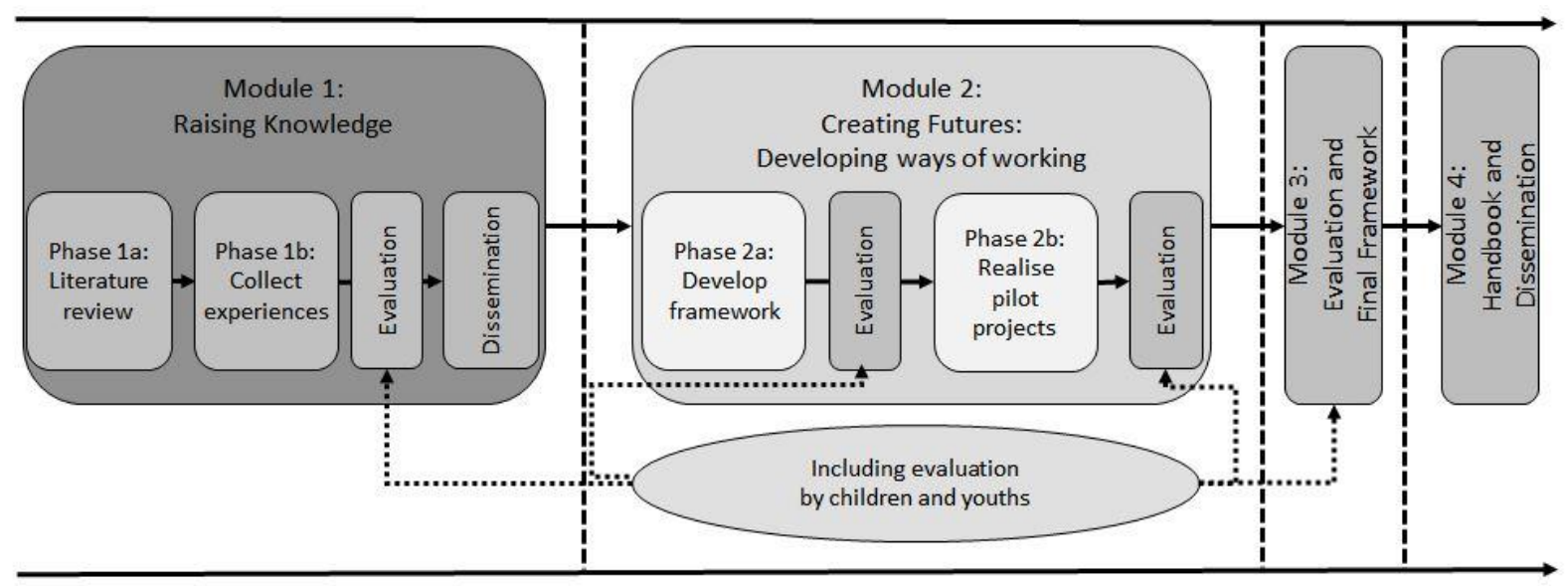

Figure 2. The project modules.

Module 1 - Raising Knowledge is aimed at gathering and reviewing knowledge about the core topic of the project and related themes. The objectives are (a) to understand how children and youth in residential care form their own ideas of a possible future; (b) to understand the necessary prerequisites to support these processes, with particular regard to personal 
International Journal of Child, Youth and Family Studies (2018) 9(1): 132-153

competencies, resources, options, and organisational conditions; and (c) to accumulate examples of good practice (as material input, not project output) and to formulate hypotheses on how these prerequisites can be developed and strengthened in the organisational context of a residential care home.

In Phase $1 a$ a literature study will be conducted. It will take into account a wide range of peer-reviewed and also "grey" literature (e.g., concepts, guidelines, and white papers).

In Phase $1 b$, focus group interviews will be conducted in Switzerland and Hungary to collect and systematise the experiences of adolescents, young care leavers, staff, and managers. Additionally, a "Young Expert Exchange" in the summer will bring together youth from the homes in both countries to collect and exchange knowledge and experiences and to collaborate on formulating recommendations. Since implicit knowledge is expected to be key, it will employ methods that access not only cognitive content (as interviews do) but also intuition, experience, creativity, mutual dynamics, perception, and association. Ideally, children would also be included in the Phase $1 \mathrm{~b}$ activities; however, that will depend on the resources available as different, age-appropriate methods, and experts competent in applying them, would be required.

The CoP, with an invited young adult from each home, will meet twice, once in Budapest and once in Zurich, to discuss findings of Phase 1, reflect on them, and develop conclusions and recommendations for the further course of the project.

Module 1 will conclude with the dissemination of a detailed final report, which will be the starting point for Module 2.

Module 2 - Creating Futures: Developing ways of working will devise organisational approaches that empower children and youth in residential care to take their development into their own hands, develop ideas of the future, pursue them actively, and realise them sustainably. It is important that these are concrete "ways of working"; that is, routines, practices, concepts, frameworks, mind-sets, and cultures that can be effectively implemented by a Child and Youth Home.

Phase $2 a$ aims to enable the participating child and youth homes to conduct a selfanalysis and to identify developmental opportunities and possibilities that are specific to the organisation. The goal of this phase is not only to develop the framework for analysis based on the results of Module 1, but also to complete analyses in each participating home and to formulate hypotheses and propose candidates for specific projects in each home. The evaluation of this phase will provide ideas for first pilot projects, which then form the basis for Phase $2 b$.

Phase $2 b$ starts with the design and implementation of one pilot project per participating child and youth home. The pilot projects are intended to be innovative, to foster change, and to result in new or improved solutions regarding organisational matters relating to the empowerment of young people (methods, attitudes, processes, etc., and the organisational 
International Journal of Child, Youth and Family Studies (2018) 9(1): 132-153

conditions that make them possible), thus contributing to improvements in the participating homes' quality of service. A key evaluation criterion will be whether the pilot projects indeed result in an increase in the homes' capacity to further the empowerment of the young people they serve.

Implementing the pilot projects will lead to a refined version of the framework produced in phase $2 \mathrm{a}$ as well as to its extension into a model that refers to aspects of organisational implementation. The evaluation of each individual pilot project will identify further opportunities for improvements specific to each child and youth home. The CoP will prepare an evaluation report that documents not only the pilot projects implemented, but also all project phases that resulted in the design and implementation of these projects. The report will apprise each participating home not only of the concrete pilot project each of the other participating homes has implemented, but also of the process by which the project identification, design, and implementation came about. As regards methods, the following activities will contribute significantly to the pilot projects and to their evaluation: focus groups and Young Expert Exchanges with children, youth, staff, and managers from each country; national CoP workshops in each country; and joint 3-day CoP workshops. The perspectives of children, youth, staff, and managers on each project will be reported and jointly evaluated. Additionally, the wider expert network will be involved in the reflection and discussion of proceedings and results at regular intervals.

Module 3 - The evaluation and final framework will produce a final report with recommendations for the participating child and youth homes. The final report will integrate the main results from Modules 1 and 2; that is, it will address the explicit knowledge base, the implicit knowledge base, and the organisational insights gained by conducting and evaluating the pilot projects. It will clearly address intended effects as well as unintended side-effects and errors, and will not only focus on organisational elements having been changed or introduced, but also on the learning processes experienced. In addition, the corresponding development steps will be described, including the expertise of children, youth, staff, managers, authorities, and the wider expert network. Recommendations for further learning and development regarding the project's focus topic, and information on the highly participatory, resource-oriented methodology of the project, will be provided to each participating home and country.

Again, the evaluation and preparation of the final report will also be supported by additional focus groups and Young Expert Exchanges with children and youth from each country, staff workshops in each home, national and binational CoP workshops with the managers, joint 3-day CoP workshops, and consultations with the wider expert network.

Module 4-Guidelines and dissemination will make the model and the report available to all FICE members, nationally and internationally, and to the public. The main objective is to offer relevant information and a model regarding the focus topic not only for all interested child and youth homes, but also for managers, staff, children, and youth, as well as academics and 
International Journal of Child, Youth and Family Studies (2018) 9(1): 132-153

students in the field. Module 4 will ensure that all relevant information becomes available and is communicated in German, Hungarian, and English. Overall, the dissemination will include peerreviewed journal articles; a practice handbook or website of similar content, illustrated with reallife examples; practice-oriented publications; and presentations and publications for a more general audience. The development of didactic materials for professional education and training for staff and managers is also considered. Recommendations or proposals for follow-up projects with a particularly high impact will be included.

\section{Subjects}

Over the three years, based on what can be planned at the present stage, it is estimated that the project will involve up to 150 members of management and staff of the participating child and youth homes, as well as approximately 400 children and youth from those homes, both in producing and reflecting on information, and in designing, implementing, and evaluating parts of the project. However, it is likely and desirable that these numbers will further increase, particularly in the context of the concrete pilot projects being designed and introduced, as several participating homes have already mentioned that, with regard to sustainability, they consider it important that all their staff and most, if not all, children and youth in their care be involved in some way.

\section{Results}

The Creating Futures project will start formally in at the beginning of 2018 if the necessary resources have become available by then. From then on, focus groups, Young Expert Exchanges, CoP meetings and, later, pilot projects, will be realised; and their results and learnings will be disseminated continually.

However, by the time the project starts formally, the CoP will have collaborated for nearly two years already, getting to know each other, coming together in national groups as well as in the joint group, establishing ways of communicating and collaborating, discussing interests, finding and defining a focus topic of mutual interest, designing the structure of the project, agreeing on methods and participants, and so on.

The first results of the project can be seen in all that is presented in this paper, in particular as regards the topic, content, design, and organisation of the project, since they all have been developed jointly by the Swiss and Hungarian participants. In fact, this paper itself and the presentation at the 33rd FICE Congress in 2016 that it is based on are important first achievements for the CoP. Most of all, though, the sustained interest and engagement of all participants over two years must be considered a success, as must be the fact that some adolescents and young adults from a home in Hungary and a home in Switzerland have reacted with enthusiasm and great interest, both to the topic of the project and to the role they can play in it. At the time of writing this paper in May of 2017, module 1 had reached the stage of organising the first focus groups and Young Expert Exchange. 
International Journal of Child, Youth and Family Studies (2018) 9(1): 132-153

The preparatory phase of the last two years has presented a number of challenges as well as strengths. To the $\mathrm{CoP}$, it has been a very significant phase, and consequently, it shall be described here, and some of its learnings cited.

All the activities of this phase have been realised despite insufficient financial resources. This has made the support that the CoP enjoys and the creativity and motivation of its members even more apparent, as ZHAW and the Hungarian Directorate General for Social Affairs and Child Protection found ways to contribute some finances and paid work hours, and the CoP members and particularly the coordinator contributed a considerable amount of voluntary work and found creative solutions for communication and collaboration when meeting in person was not possible. The establishment of a group of experts dedicated to, and able to collaborate in, realising the project was a prerequisite even more fundamental than financial resources to the project's success.

In other aspects, too, both challenges and strengths have become apparent. As a Hungarian participant said, "Thinking beyond our everyday tasks and experiences and leaving our comfort zones is very positive and, at the same time, a challenge."

Language is perhaps the most immediately obvious challenge, as $\mathrm{CoP}$ members in the two countries speak either Hungarian or German and have varying degrees of confidence and fluency in English (though several CoP members report improvements in their language skills thanks to the collaboration, some of them remarkable). All documents, including minutes of meetings and communications, have to be made available in both German and English and translated to Hungarian and vice versa.

The coordinator as well as the CoP members from both countries soon noticed that contexts and habits are indeed diverse. This is not only true on the level of aspects such as laws and regulations, or the history of child and youth care, but also with regard to aspects such as how discussions are structured, decisions are taken, and conflicts are addressed and resolved. Furthermore, the fact that all participants are subject to particular conditions, relationships, and hierarchies, and thus experience diverse possibilities and constraints in their professional roles and contexts, is apparent and impacts the collaboration, sometimes favourably, and sometimes less so.

Remarkably, all members of the CoP have been taking on these challenges with patience and good humour, granting each other a considerable amount of trust and displaying professional and reliable behaviour as well as a great willingness to contribute to moving the collaboration forward. Regular metacommunication continues to be necessary in order to find shared ways forward. In fact, members have mentioned repeatedly that the ensuing discussions have contributed to "opening their horizons".

In both countries, the members have given the coordinator access to their organisations, including staff and children and youth, and have explained their contexts and work. As the 
International Journal of Child, Youth and Family Studies (2018) 9(1): 132-153

coordinator had no previous experience of Hungary, the generosity and openness with which child and youth home directors, staff, children, adolescents, and young adults, as well as members of the Directorate General, showed and explained their worlds to her was much appreciated. In Switzerland, too, she was welcomed most kindly, and generously given opportunities for open exchange with directors, staff, and youth, as well as with the official responsible for child and youth homes at the Authority for Youth and Occupational Counselling. As the coordinator, an academic at a university of applied sciences, is tasked with coordinating a $\mathrm{CoP}$ and a project intended as being "from practice for practice", this engagement of the practice partners is of vital importance to her ability to fulfil her role appropriately and contribute the necessary academic knowledge and skills in a suitable and fruitful manner.

It has been noticeable that participants from each country have felt inspired by some of their experiences during discussions or visits to homes or authorities in the other country. For example, one of the Swiss directors wrote, "I am impressed with the personal commitment of the partners from Hungary and their pioneering spirit."

All members of the CoP have demanding jobs and work intense schedules with little free time. The Swiss group members have repeatedly mentioned the extent to which their field is in motion, and the challenges this poses for the homes. For example, the introduction of a new law for child and youth homes is planned for the Canton of Zurich in 2018. The law will bring with it not only a change in finance models but also a paradigm shift regarding placements, as an attempt will be made to focus more on what each young person needs and less on the services that are available, while an increased preference will be given to ambulatory over residential services. Child and youth homes "will become more like just one service among many", as one of the participating directors said (personal communication, June 17, 2016) . "They may experience difficulties in taking in enough children and youths to remain running; some homes even may have to close. Of course, it is not impossible that, over time, it will become apparent that placements in residential care continue to be necessary."

These changes lead to an increase in pressure and workload in the homes as they are reviewing their services to be ready for positioning themselves once the new law comes into force. As regards an additional concrete project or initiative within a Swiss-Hungarian collaboration, a wish to do something that would be immediately useful in this period of change became apparent.

Why, under such circumstances, would the CoP members wish to take on the challenge of jointly building up this $\mathrm{CoP}$ and developing the Creating Futures project together with colleagues from quite a different context?

On an individual level, a "curiosity for new things" or, "I hope to hear and learn new things" have been mentioned by members from both countries. As regards the professional role, 
International Journal of Child, Youth and Family Studies (2018) 9(1): 132-153

the Hungarian participants (personal communication, July 2016) have mentioned that they felt that the CoP allowed them to:

- get a wider, deeper view of approaches, methods, and techniques in residential child care;

- share and implement the new learnings in daily practice;

- enrich personal knowledge of theories and practices of child and youth care;

- share their own points of view and know-how with foreign professionals, develop together new know-how and innovative methods and techniques, and support each other in implementation; and

- contribute to increased respect for child and youth care and those who work in it.

On the part of the Swiss participants (personal communication, July 2016), statements such as the following were made:

I assume that culture, degree of professionalization, and financial investment vary between the two countries. These differences offer an opportunity for new perspectives in the pedagogical work.

How can my work succeed in stimulating motivation for change and learning in adolescents? Maybe the different social contexts help us to think differently about these questions.

It is enjoyable and fruitful for me to step outside my daily work every now and again and come to these meetings and reflect about topics of relevance together with colleagues that I have not had much contact with before. ${ }^{12}$

When offered the possibility of joining the collaboration, another child and youth home director (personal communication, March 2017) said, "What I really like about this idea is that it offers an experience of self-efficacy to all who are involved, and everybody goes on a learning journey together" 13 .

\section{Conclusion}

Creating Futures is a project of binational, multicontextual, multilingual, multicultural collaboration that involves diverse stakeholders in a participatory fashion, and takes a somewhat unusual methodological path in the pursuit of a complex topic. As such, it has required an intense preparatory phase, which has been lengthy not only due to the complexity of the endeavour but also to the limited resources available.

\footnotetext{
12 Translated from German by the corresponding author.

13 Translated from German by the corresponding author.
} 
These characteristics have been a topic in several conversations between members of the $\mathrm{CoP}$ or between individual members and their employers who perhaps are more used to the more common type of research where either an academic drafts a project and then asks for informants from practice organisations, or a practice organisation has a very specific question for which it asks academics to render research services. Although such projects can be complex too, they depend less on interpersonal and joint processes than the path that this CoP has chosen. The members of the CoP feel, however, that their chosen path has many benefits, and that any perceived "lack of speed" of the initial phase will likely translate into greater stability and sustainability of the project as well as into rich and diverse content and many sources of creativity and inspiration.

Developing a mutual understanding of what it means to work as partners who jointly and with equal rights and obligations take responsibility for the functioning of the CoP and its project remains a challenge and a continuing process.

As this is a participatory and exploratory project designed as a collaborative learning and development process, its outcomes and impact cannot be predicted in their entirety. Consequently a not inconsiderable amount of trust, courage, flexibility, and creativity but also time and mental energy, are required of each member of the CoP.

The endeavour of the CoP will remain complex and will continue to bring its share of challenges and achievements, difficulties and joys. Certainly, though, it will be a learning journey which, if carried out successfully, will be undertaken jointly by the participating "young" and "old" experts learning and developing together, encouraging and inspiring each other, and collaborating on making a contribution to the children and youth in residential care who are continually building their lives, and to the homes that support and empower them in taking their development into their own hands, developing their own ideas of the future, pursuing these actively, and realising them sustainably. 
International Journal of Child, Youth and Family Studies (2018) 9(1): 132-153

\section{References}

Barros, R. (2006). Em busca de um projeto de vida [In search of a life project]. In M. V. Baptista (Ed.), Abrigo. Comunidade de acolhida e socioeducação[Child and youth home.

Community of care and socioeducation] (pp. 99-100). São Paulo, Brazil: Instituto Camargo Corrêa.

Bommes, M., \& Scherr, A. (2012). Soziologie der Sozialen Arbeit. Eine Einführung in Formen und Funktionen organisierter Hilfe [Sociology of social work. An introduction to the forms and functions of organised assistance] (2nd ed.). Weinheim, Germany: Beltz Juventa.

Burgund, A., \& Rácz, A. (2015). Comparative analyses on youth care in Hungary and Serbia. Metzetek, 4(2), 97-106. Retrieved from http://metszetek.unideb.hu/files/metszetek\%202015_2_07_burgund.pdf

Drepper, T., \& Tacke, V. (2010). Unterrichtsinteraktion: Strukturelle Konditionierung und Eigendynamik [Interaction in teaching: Structural conditioning and momentum]. In T. Klatetzki (Ed.), Soziale personenbezogene Dienstleistungsorganisationen. Soziologische Perspektiven [Person-oriented social service organisations. Sociological perspectives] (pp. 241-284). Wiesbaden, Germany: Springer VS.

Esser, K. (2010). Die retrospektive Bewertung der stationären Erziehungshilfe durch ehemalige Kinder und Jugendliche. Ein Beitrag zur Qualitätsentwicklung und Wirkungsorientierung [The retrospective appraisal of residential care by former children and adolescents. A contribution to quality development and impact orientation]. Köln, Germany: Universität zu Köln.

FICE Standards Developed by Young Care Leavers. (2016). Retrieved from FICE International Federation of Educative Communities: https://www.ficeinter.net/statements

Fretschner, R. (2011). Soziales Dienstleistungsmanagement [Social services management]. In A. Fritze, B. Maelicke, \& B. Uebelhart (Eds.), Management und Systementwicklung in der Sozialen Arbeit [Management and systems development in social work] (pp. 74-87). Baden-Baden, Germany: Nomos.

Gabriel, T., \& Stohler, R. (2008). Transitions to adulthood of young care leavers in Switzerland. In M. Stein \& H. Ward (Eds.), Young peoples`s transitions from care to adulthood. International research and practice (pp. 197-208). London, UK: Kingsley.

Macsenaere, M., \& Esser, K. (2012). Was wirkt in der Erziehungshilfe? Wirkfaktoren in Heimerziehung und anderen Hilfearten [What works in child and youth services? Impact factors in residential care and other types of assistance]. München, Germany: Ernst Reinhart Verlag. 
International Journal of Child, Youth and Family Studies (2018) 9(1): 132-153

Piber, H. (2014). Das Trigon-Organisationsmodell [The Trigon organisational model]. In F. Glasl, T. Kalcher, \& H. Piber (Eds.), Professionelle Prozessberatung [Professional process guidance] (3rd ed., pp. 73-89). Bern, Switzerland: Haupt.

Piller, E. M., \& Schnurr, S. (2013). Forschung zur schweizerischen Kinder- und Jugendhilfe. Eine Einleitung [Research on Swiss child and youth care. An introduction]. In E. M. Piller, \& S. Schnurr (Eds.), Kinder- und Jugendhilfe in der Schweiz: Forschung und Diskurse [Child and youth care in Switzerland: Research and discourses] (pp. 7-19). Wiesbaden, Germany: Springer VS.

Sievers, B., Thomas, S., \& Zeller, M. (2014). Nach der stationären Erziehungshilfe. Care Leaver in Deutschland. Internationales Monitoring und Entwicklung von Modellen guter Praxis zur sozialen Unterstützung für Care Leaver beim Übergang ins Erwachsenenalter [Afer residential care. Care leavers in Germany. International monitoring and development of models of good practice regarding social support of care leavers in transition to adult age.] Frankfurt, Germany: Internationale Gesellschaft für erzieherische Hilfen \& University of Hildesheim. Retrieved from http://forschungsnetzwerk-erziehungshilfen.de/wpcontent/uploads/2016/04/Abschlussbericht_final_03-2014.pdf

Stangl, W. (n.d.). Motivation. In W. Stangl, Online encyclopedia of psychology and education. Retrieved from http://lexikon.stangl.eu/337/motivation/

Stohler, R., \& Gehrig, M. (2015). Homeless young adults in the Swiss social assistance system: Evaluation of an institution for homeless young adults who have no daily structure. International Journal of Child, Youth and Family Studies, 6(3), 478-493. doi:10.18357/ijcyfs.63201513600

Wenger-Trayner, E., \& Wenger-Trayner, Beverly. (2015, April 15). Communities of practice. A brief introduction. Retrieved from http://wenger-trayner.com/wpcontent/uploads/2015/04/07-Brief-introduction-to-communities-of-practice.pdf

Wohlgemuth, A. C. (1991). Das Beratungskonzept der Organisationsentwicklung : neue Form der Unternehmungsberatung auf Grundlage des sozio-technischen Systemansatzes [The consultancy concept of organisational development: A new form of management consultancy based on the socio-technical systems approach] (3rd ed.). Bern, Switzerland: Haupt. 